\title{
Rekonstruksi Identitas Sosial Kebudayaan di Perkotaan
}

\section{Studi Kasus Kota Pekanbaru, Indonesia}

\author{
Yohannes Firzal \\ Program Studi Arsitektur, Universitas Riau, Pekanbaru, Indonesia \\ yfirzal@eng.unri.ac.id \\ doi.org/10.29080/eija.v5i1.533
}

\begin{abstract}
Identity of place can be changed and reconstructed. This is seen as capable of supporting dynamic changes in real life through the transformation of practices and the articulation of social relations. In this sense, the identity is affected by culture and cultural production, and is an unfixed, unfinished and varying process that affects both the place and society. By using a qualitative approach, this study investigates the influence of Malay culture on the identity in Pekanbaru city. The field data are grouped, analysed, and interpreted within an iterative process to expand understanding of the processes of reconstructing identity, and how the identity on the margins becomes an exclusive set of collective identities. Thus, this paper shows connections between the culture and identity of place which is identified through architecture and socio-cultural change in urban society
\end{abstract}

Keywords: Identity, Urban Architecture, Socio-Cultural Change

\begin{abstract}
Abstrak: Identitas suatu tempat pada hakikatnya dapat diubah dan dibentuk. Kondisi seperti ini dapat dimungkinkan sebagai bentuk upaya untuk mengakomodir perubahan keseharian yang terjadi yang terbentuk oleh transformasi dan artikulasi hubungan sosial. Dalam konteks ini, identitas tempat tersebut akan berkaitan erat dengan pengaruh budaya dan tradisi yang berlaku; sesuatu yang bersifat tidak tetap, belum berakhir dan memiliki berbagai variasi bentuk lainnya yang sudah tentu mempengaruhi tempat dan kehidupan masyarakat tempatan. Melalui pendekan penelitian kualitatif, penelitian ini mencari pengaruh budaya Melayu pada identitas sosial kebudayaan di Kota Pekanbaru. Data lapangan dikelompokkan, dianalisis, dan diolah melalui proses iterasi berulang guna memahami bagaimana proses rekonstruksi identitas sosial kebudayaan terjadi, dan bagaimana juga identitas budaya tertentu menjadi dasar dalam proses rekonstruksi identitas ini. Penelitian ini pada akhirnya dapat menyimpulkan bahwa hubungan antara budaya dan identitas dapat dijelaskan melalui arsitektur dan perubahan sosial kebudayaan yang terjadi di kehidupan perkotaan.
\end{abstract}

Kata Kunci: identitas, arsitektur perkotaan, perubahan sosial kebudayaan

\section{PENDAHULUAN}

Identitas tempat selalu menjadi topik bahasan menarik. Untuk memahami hal ini, perlu kiranya mengenal terlebih dahulu dua konsep dasar identitas, yaitu konsep jati diri (existing or being concept), dan konsep proses (becoming concept). Konsep jati diri menjelaskan bahwa identitas tidak dapat dirumuskan dari suatu konsep luas dan juga tidak dapat juga direpresentasikan melalui konsep yang lebih rendah (Heidegger, 2011). Namun suatu identitas bergantung pada konsepsi tempatan tertentu yang mempertimbangkan lokasi sebagai bagian yang tidak terpisahkan, seperti sense of place; sering dijadikan sebagai acuan awal (precognitive) dengan artian yang diperluas, dan mengabaikan perkembangan sosial tempatan (Dovey, 2014). Sehingga konsep jati diri akan cenderung menuju bentuk tunggal, tetap, dan statis yang dapat diidentikkan dengan bentuk ketertutupan dan menolak pengaruh luar (Massey, 2013). Secara sederhana, menurut konsep jati diri, identitas tidak dapat diubah; menolak pengaruh luar dan nyaman dengan kondisi yang dimilikinya. Konsep dasar identitas seperti ini cukup banyak berkembang dan diterjemahluaskan seperti ide kemurnian (purity), keindahan (picturesqueness), semangat lokal (local spirit), and nilai hakiki tempatan (genius loci) (Jive'n \& Larkham, 2003; Norberg-Schulz, 1980).

Sedangkan menurut konsep proses, identitas digambarkan sebagai sesuatu yang tidak begitu jelas, abstrak, dan dipengaruhi oleh berbagai bentuk pemikiran dan isu (Deleuze \& Guattari, 2004). Dalam pengertian dasar; suatu identitas menjadi hal yang dapat dan sangat dimungkinkan untuk dibentuk kembali (Ballantyne, 2007; Deleuze \& Guattari, 2004). 
sehingga suatu identitas dapat berubah atau diubah, dan kondisi ini ditentukan oleh keterkaitan dari pada esensi (DeLanda, 2006). Lebih lanjut, identitas juga dapat dijelaskan sebagai suatu praktek perubahan yang terbentuk melalui keterlibatan simbolis kapital dari budaya dan produk kebudayaan (Dovey, 2010).

Dalam penelitian ini, rekonstruki identitas sosial kebudayaan di perkotaan disintesa berdasarkan konsep proses (becoming concept). Identitas dalam konteks ini didefinisikan sebagai suatu bentuk penekanan dari hubungan sosial yang muncul melalui interaksi antara satu dengan lainya, dan suatu hal yang dapat diperbaharui (Massey, 2013). Identitas dirumuskan dalam artian lebih bebas (outwardlooking), jamak (multiple), dan terbuka (open) dengan karakter yang terbentuk melalui keterkaitan dan interaksi (Dovey, 2010).

Oleh karena terbentuk secara sosial, maka konsepsi identitas menjadi sesuatu hal yang sedang berproses; dapat berubah, dibentuk, dan belum selesai (Ballantyne, 2007; Deleuze \& Guattari, 2004; Dovey, 2010). Hal ini akan mengambarkan suatu bentukan proses secara terus menerus yang tidak berujung, sehingga identitas tersebut seharusnya didefinisikan sebagai kegiatan pembetukan (practice) dari pada sesuatu telah ada (pregiven), menghargai arti penting proses (valorises routes) dari pada hal didapat (roots), sesuatu yang mengalir (flows) dari pada keseimbangan (stasis). Dalam pandangan ini, maka suatu tempat akan dapat mengakomondasi perbedaan dan terbuka akan kemungkinan baru yang sedang berlangsung (Dovey, 2014).

Seiring dengan era reformasi, pengukuhan identitas tempat dan budaya lokal menjadi topik penting dalam kaitannya dengan program desentralisasi (Reid, 2001). $\mathrm{Hal}$ ini tercermin dengan melegalisasi budaya Melayu sebagai referensi budaya utama di Riau sejak tahun 2000 (Pemprov Riau, 2000) dan Kota Pekanbaru dimulai sejak tahun 2001 (Pemko Pekanbaru, 2001). Meskipun terdapat asumsi bahwa Melayu berasal dari Kalimantan (Adelaar, 2004), beberapa peneliti sepakat bahwa budaya Melayu berasal dan terbentuk di pantai timur Sumatra, Semenanjung Malaya, dan rangkaian kepulauan diantaranya (Milner, 2011; Raffles, 1835; Reid, 2001). Sehingga tidak mengherankan jika saat ini Riau diyakini sebagai pusat identitas dan budaya Melayu untuk konteks Indonesia (Long, 2013).

Pada prakteknya, desentralisasi saat ini juga telah menjelma sebagai salah satu program radikal (Long, 2013) Di Pekanbaru, orang Melayu bukanlah etnis mayoritas, dan berjumlah $26 \%$ dari satu jutaan populasi kota (BPS Pekanbaru, 2019). Dengan menempatkan budaya Melayu sebagai referensi utama, hal ini terbukti telah mempengaruhi tidak hanya identitas kota, tetapi juga kehidupan bersosial budaya masyarakat. Kondisi ini juga telah memicu permasalahan baru yang dikenal sebagai postrevolutionary nationalism (Reid, 2001); periode yang menempatkan klaim etnis tertentu untuk menerapkan pola dan referensi kebudayaan tertentu (Melayu) pada kepentingan individu dan keragaman kebudayaan yang ada.

Lebih jauh lagi, radikalisasi juga terjadi dalam internalisasi etnis Melayu itu sendiri. Hal ini terbukti dengan adanya upaya mendefinisi ulang konsep identitas Melayu kedalam definisi sempit (Milner, 2011); disebut orang Melayu jika mampu dalam tiga hal yaitu berbahasa Melayu, muslim, dan beradat Melayu. Oleh karenanya, topik penelitian terkait identitas tempat ini menjadi menarik untuk dilakukan di Kota Pekanbaru yang dikenal dengan kehidupan multietnisnya.

\section{METODE PENELITIAN}

Penelitian ini merupakan hasil kajian dengan menggunakan pendekatan kualitatif. Pendekatan kualitatif dapat menelisik kondisi dan sumber permasalah sosial (Patton, 2002), dengan menitikberatkan pada pemahaman arti dan proses berdasarkan berbagai material empiris (Groat \& Wang, 2002). Pendekatan kualitatif juga memungkinkan untuk mengkombinasikan berbagai metode operasional penelitian dalam mengumpulkan dan menganalisa data, baik itu bersumber pada orang, artefak, peristiwa, ataupun interprestasi (Creswell, 2003; Groat \& Wang, 2002).

Data utama penelitian dikumpulkan dari studi lapangan dan dikelompokkan dalam tiga bentuk data: bukti fisik, interprestasi responden, dan dokumen tertulis. Data utama ini didapat melalui berbagai metode operasional seperti observasi, wawancara semi-terstruktur, PEI, arsip, catatan lapangan, diskusi kelompuk, dan dokumentasi lapangan. Berdasarkan pengalaman studi lapangan, metode operasional wawancara memberikan manfaat lebih untuk memaksimalkan pengumpulan data dan informasi. Dalam hal ini, faktor kedekatan emosional dan kesamaan latar budaya terbukti dapat menjembatani kebuntuan dan kekakuan; terutama berkaitan dengan topik bahasan sensitif (Richards, 2009; Whyte \& Whyte, 1984). Secara umum, kajian dengan menggunakan pendekatan penelitian kualitatif dapat menempatkan peneliti untuk berperan aktif dalam situasi yang sedang diteliti (Richards, 2009).

\section{HASIL DAN PEMBAHASAN}

\subsection{Transformasi Arsitektur Kota}

Arsitektur dalam konteks perkotaan tidak dapat membingkai suatu identitas secara pasti. Melainkan, arsitektur membutuhkan translasi ke bentuk yang dapat diamati atau bentukan lainnya. Dalam pengertian dan kaitan dengan penelitian ini, hubungan 
antara budaya dan arsitektur dapat diidentifikasi melalui fungsi simbol, rancang bangun, dan hubungan keterkaitan antara perubahan sosial budaya dalam kehidupan keseharian. Dengan demikian, arsitektur kota dapat diposisikan perannya dalam konteks membentuk identitas kota melalui simbol kapital dan simbol dominasi (Bourdieu, 1984), dan pada akhirnya arsitektur kota tersebut dapat menjadi produk dari cerminan masa depan dan perubahan sosial (Dovey, 2010; Findley, 2005).. Hal ini sesuai dengan pandangan (Hutcheon, 1999) yang menyatakan bahwa kepercayaan dan nilai kebudayaan akan memberikan kekuatan dalam membentuk fisik dan pergerakan sosial. Dalam konteks rekonstruksi identitas arsitektur kota maka dapat ditinjau dari dua hal: representasi fisik arsitektural kota, dan perubahan kehidupan sosial masyarakat perkotaan.

Dengan meletakkan budaya Melayu sebagai referensi utama di Kota Pekanbaru, representasi fisik kota telah mengalami perubahan. Hal ini tercermin dari perubahan dan penyesuaian wajah arsitektur kota. Sebagai bagian dari budaya, arsitektur Melayu diimplementasikan pada ekspresi visual bangunan kota sejak tahun 2000 hingga saat ini. Secara umum, fenomena ini dapat dipahami sebagai bagian upaya untuk mencari simbol dominan melalui perubahan tampilan arsitektural bangunan. Dalam perkembangannya, implementasi arsitektur Melayu ini juga mulai mengalami berbagai permasalahan tersendiri. Demikian pula dengan kehidupan masyarakat di Kota Pekanbaru yang mencoba menyelaraskan dengan nilai-nilai budaya Melayu, baik dalam kehidupan pribadi atau pun dipublik. Dalam konteks ini, masyarakat perkotaan juga melakukan penyesuaian dengan perubahan arsitektur kota Pekanbaru. Namun demikian, kehidupan multietnis kota para prakteknya juga telah memberikan perubahan dua arah dalam implementasi nilai-nilai budaya Melayu tersebut.

\subsection{Representasi Arsitektur Melayu}

Visi Kota Pekanbaru, "Terwujudnya Kota Pekanbaru Sebagai Pusat Perdagangan Dan Jasa, Pendidikan serta Pusat Kebudayaan Melayu, Menuju Masyarakat Sejahtera yang Berlandaskan Iman dan Taqwa" ditujukan untuk menjadikan Pekanbaru sebagai pusat kebudayaan Melayu, dan dijabarkan dalam lima Misi Pembangunan kota (Pemko Pekanbaru, 2001). Dalam konteks ini, salah satu dari ke lima misi ini bersinggungan langsung dengan arsitektur, yang berbunyi: '...kehendak menjadikan Kota Pekanbaru sebagai pusat kebudayaan Melayu antara lain akan diarahkan kepada tampilnya identitas fisik bangunan yang mencerminkan kepribadian daerah, adanya kawasan beridentitas adat Melayu... '(Pemko Pekanbaru, 2001).

Dalam pelaksanaannya, pemerintah Kota
Pekanbaru secara legal melalui peraturan daerah (perda) menginstruksikan penerapan arsitektur Melayu-Riau untuk ekspresi bangunan kota. Hal ini berlaku tidak hanya untuk bangunan pemerintahan saja (gambar 1), tetapi juga bagi sebagian besar bangunan publik dan swasta (Gambar 2). Sehingga, dalam kurun waktu antara 2000-2010, semua bangunan pemerintah kota telah melakukan renovasi pada tampilan ekspresi visual dengan menyesuaikan terhadap perda bangunan kota.

'... arsitektur tradisional Melayu telah menjadi referensi utama untuk mengekpresikan nilai Melayu pada bangunan perkotaan ... ' (Walikota, Responden 37, Hasil Wawancara)

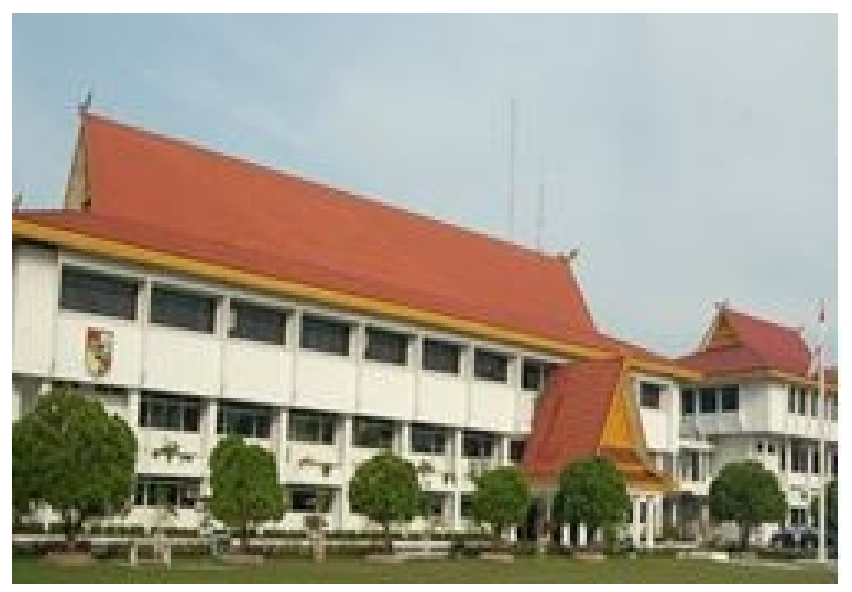

Gambar 1. Kantor Walikota sebagai Salah Satu Model Arsitektur Melayu di Pekanbaru (Sumber: Dokumen peneliti, 2018)

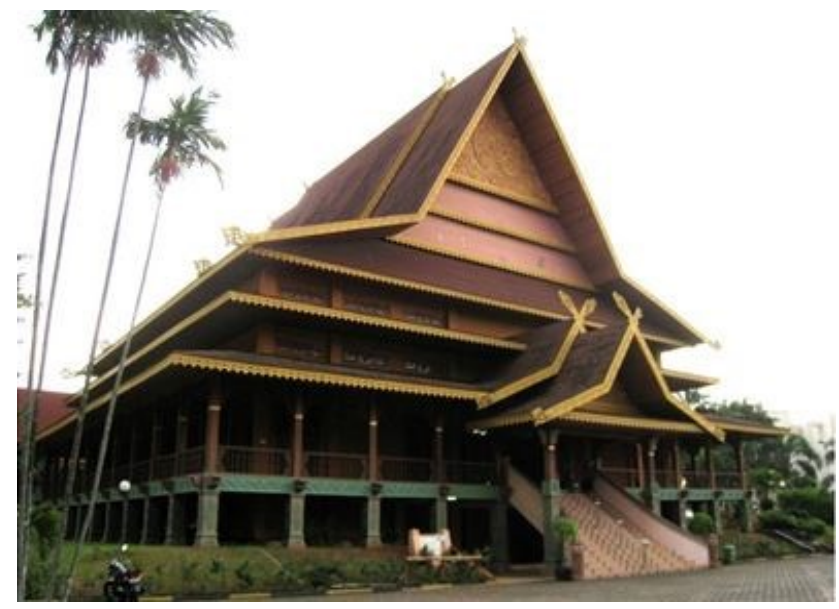

Gambar 2. Anjungan Rumah Tradisional Melayu (Sumber: Dokumen peneliti, 2018)

Implementasi arsitektur Melayu-Riau pada kenyataannya telah membawa konsekuensi serius tidak hanya pada wajah arsitektur kota, namun juga bagi arsitektur Melayu, bagi pemerintah, dan juga bagi para pelaku konstruksi dan arsitek profesional. Fenomena ini dapat ditinjau dan dikaji dari berbagai 
sudut pandang seperti mendefinisikan arsitektur Melayu tradisional, arsitektur Melayu kontemporer. Pada akhirnya, transformasi ekspresi wajah arsitektur di Kota Pekanbaru bertujuan mencari identitas yang dapat diterima sebagai identitas arsitektur kolektif yang sesuai dengan budaya Melayu dan menunjang perkembangan arsitektur.

\subsection{Kehidupan Sosial-Budaya Multietnis}

Untuk mewujudkan kota Pekanbaru sebagai pusat kebudayan Melayu, hal ini membawa dampak nyata dalam perubahan kehidupan keseharian masyarakat. Meskipun multietnis, masyarakat kota terus mencoba untuk menerapkan nilai budaya dan tradisi Melayu untuk mejadi bagian identitas. Meskipun tidak dapat berlaku secara sukarela dan sadar, pemerintah terus melakukan upaya legalisasi melalui peraturan daerah untuk menerapkan dan mengimplementasi budaya Melayu bagi masyarakat seperti melalui kegiatan komunal kota, pakaian seragam sekolah dan kantor, perayaan budaya serta tunjuk ajar (gambar 3).

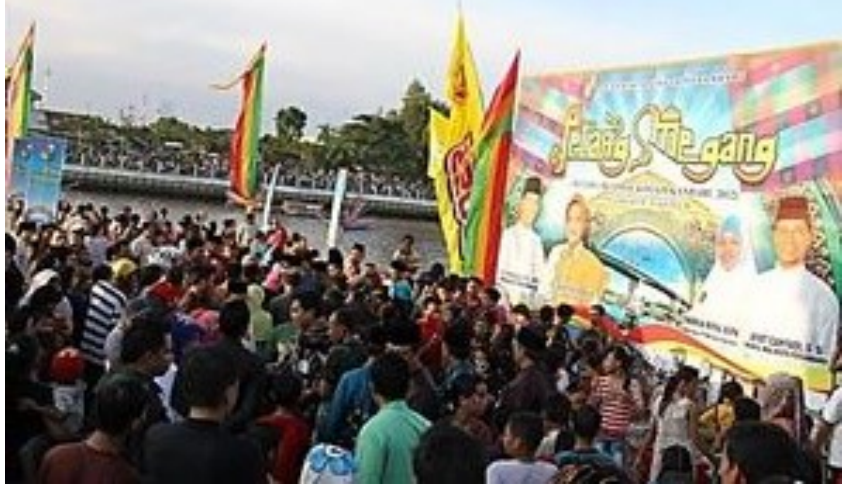

Gambar 3. Tradisi Petang Megang Melayu menjadi even tahunan kota (Sumber: Dokumentasi peneliti, 2018)

Dalam konteks kehidupan multietnis, implementasi nilai budaya Melayu tidak dapat diterapkan secara penuh dan tegas, tetapi melalui negosiasi sosial berkelanjutan ditengah masyarakat. Hal ini tercermin dengan bentuk kesepakatan yaitu nilai budaya dan tradisi Melayu dapat diterima sebagai referensi utama kehidupan bermasyarakat, namun pemerintah kota tetap memberikan ruang gerak keleluasaan untuk tumbuh kembang bagi ekspresi dan tradisi budayabudaya lainnya. Dengan demikian, tidak hanya toleransi kehidupan keseharian saja yang tercapai, tetapi juga kehidupan bersosial budaya.

'...setiap orang disini [Pekanbaru] harus mengimplementasikan nilai budaya Melayu, namun dalam waktu yang bersamaam juga bertanggung jawab untuk menjaga dan mengembangkan budaya yang diwariskan oleh nenek moyang mereka masingmasing ...' (Responden 19, Hasil Wawancara)

\section{KESIMPULAN}

Fenomena rekonstruksi identitas di Kota Pekanbaru, tidak hanya terkait dengan perubahan ekspresi wajah kota pada bangunan fisik semata. Namun, perubahan kehidupan sosial budaya masyarakat perkotaan juga memberikan peranan dan dampak yang besar. Terlepas dari konsekuensi yang timbul, upaya rekonstruksi identitas ini menuju suatu kesepakatan baru yaitu identitas kolektif yang disesuai dengan budaya Melayu dalam konteks multientnis kekinian. Sehingga upaya transformasi identitas tempat ini dapat diterima secara luas. Hal ini sesuai dengan pandang (Hall, 1989) yang menyatakan bahwa 'it is necessary to find a new identity which has not lost hold of the place and the ground from which we can speak, yet it is no longer contained within that place as an essence'.

\section{DAFTAR PUSTAKA}

Adelaar, K. A. (2004). Where does Malay come from? Twenty years of discussions about homeland, migrations and classifications. Bijdragen Tot de Taal-, Land- En Volkenkunde / Journal of the Humanities and Social Sciences of Southeast Asia, 160(1), 1-30. doi: 10.1163/22134379-90003733

Ballantyne, A. (2007). Deleuze \& Guattari for Architects. Abingdon: Routledge.

Bourdieu, P. (1984). Distinction: A Social Critique of the Judgement of Taste (New Ed.). London: Harvard University Press.

BPS Pekanbaru. (2019). Pekanbaru in Figure 2018. Retrieved 26 April 2019, from https://pekanbarukota.bps.go.id/index.php/kepen dudukan

Creswell, J. W. (2003). Research Design: Qualitative, Quantitative, and Mixed Methods Approaches (2nd Ed). California: SAGE Publications.

DeLanda, M. (2006). A New Philosophy of Society: Assemblage Theory and Social Complexity. London: Continuum International Publishing Group.

Deleuze, G., \& Guattari, F. (2004). A Thousand Plateaus: Capitalism and Schizophrenia. London: Continuum.

Dovey, K. (2010). Becoming Places: Urbanism/architecture/identity/power. Routledge.

Dovey, K. (2014). Framing Places: Mediating Power in Built Form (2nd Ed). London: Routledge.

Findley, L. (2005). Building Change: Architecture, Politics and Cultural Agency. London: Psychology Press.

Groat, L. N., \& Wang, D. (2002). Architectural Research Methods. New York: John Wiley \& Sons. 
Hall, S. (1989). Ethnicity: Identity and Difference. Radical America, 23(4).

Heidegger, M. (2011). Existence And Being. Read Books Ltd.

Hutcheon, P. D. (1999). Building Character and Culture. Westport: Greenwood Publishing Group.

Jive'n, G., \& Larkham, P. J. (2003). Sense of Place, Authenticity and Character: A Commentary. Journal of Urban Design, 8(1), 67-81. doi: 10.1080/1357480032000064773

Long, N. J. (2013). Being Malay in Indonesia: Histories, Hopes and Citizenship in the Riau Archipelago. Copenhagen: NUS Press.

Massey, D. (2013). Space, Place and Gender. John Wiley \& Sons.

Milner, A. (2011). The Malays. Chichester: John Wiley \& Sons.

Norberg-Schulz, C. (1980). Genius loci: Towards a phenomenology of architecture. New York: Rizzoli.

Patton, M. Q. (2002). Qualitative Research \& Evaluation Methods. SAGE.

Pemko Pekanbaru. (2001). Visi Kota Pekanbaru. Retrieved 8 March 2019, from http://pekanbaru.go.id/p/hal/visi-kota

Pemprov Riau. (2000). Visi Dan Misi Provinsi Riau. Retrieved 12 March 2019, from https://www.riau.go.id/home/content/858/visi-danmisi

Raffles, S. (1835). Malay Annals: 2012 Ed. Memphis: General Book LCC.

Reid, A. (2001). Understanding Melayu (Malay) as a Source of Diverse Modern Identities. Journal of Southeast Asian Studies, 32(3), 295-313. Retrieved from JSTOR.

Richards, L. (2009). Handling Qualitative Data: A Practical Guide (2nd Ed). London: SAGE.

Whyte, W. F., \& Whyte, K. K. (1984). Learning from the Field: A Guide from Experience. Beverly Hills: SAGE. 